\title{
Mitogen-activated protein kinases as glucose transducers for diabetic complications
}

\author{
D. R. Tomlinson \\ Division of Neuroscience, School of Biological Sciences, University of Manchester, Manchester, UK
}

\section{Abstract}

The damaging effects of glucose on the cells which contribute to the development of diabetic complications are ill-understood. There are three major hypotheses - the sorbitol pathway, non-enzymatic glycation of proteins and increased oxidative stress and many examples illustrate inter-connections between the three. It is suggested that these pathways, together with other biochemical anomalies arising from hyperglycaemia, can synergise by sharing the capacity to activate mitogen-activated protein kinases (MAP kinases) and that these enzymes in actual fact form glucose transducers. The more recent hypothesis, namely that activation of a specific isoform of protein kinase $\mathrm{C}$ (PKC) underpin damaging changes in retinopathy and neuropathy, can also be relat- ed because protein kinase $\mathrm{C}$ is an effective activator of mitogen-activated protein kinases. These latter kinases phosphorylate transcription factors, which in turn alter the balance of gene expression. In this way they can alter cellular phenotype, promote division or increase production of extracellular material. In short, mitogen-activated protein kinases have the capacity to trigger all the cellular events necessary for the development of diabetic nephropathy, retinopathy and neuropathy and it is suggested that their pharmacological modulation might provide therapeutic control of these conditions. [Diabetologia (1999) 42: 1271-1281]

Keywords Nephropathy, neuropathy, retinopathy, hyperglycaemia, MAP kinase, ERK, JNK, p38, protein kinase $\mathrm{C}$, aldose reductase.
The results of the Diabetes Control and Complications Trial [1] emphatically confirmed the heroic studies of Jean Pirart [2-4], showing that poor control of

Received: 23 June 1999 and in revised form: 21 July 1999

Corresponding author: Professor D. R. Tomlinson, Division of Neuroscience, School of Biological Sciences, University of Manchester, Stopford Building 1.124, Oxford Road, Manchester M13 9PT, UK

This review is based upon the Golgi Lecture given during the 34th Annual Meeting of the EASD, Barcelona, September 1998 Abbreviations: ERK, Extracellular signal regulated kinase; JNK, c-jun N-terminal protein kinase; GLA-LA, diester of gamma linolenic acid and alpha-lipoic acid; GSH, reduced glutathione; MAP kinase, mitogen-activated protein kinase; NGF, nerve growth factor; $\mathrm{PKC}$, protein kinase $\mathrm{C}$; RAGE, receptors for advanced glycation end-poducts; VEGF, vascular endothelial growth factor. glycaemia in Type I (insulin-dependent) diabetes mellitus predisposes patients to chronic complications. This has led to the tacit assumption that glucose, at supranormal concentrations, is the agent of damage. Participation of hypoinsulinaemia or other manifestations of poor control cannot be discounted but glucose itself certainly has the capacity to disturb biosystems. It can do this in a variety of ways, so that hypotheses to explain specific complications - retinopathy, nephropathy and neuropathy - starting from high glucose are tenable, testable and, therefore, useful.

Figure 1 presents a simple generic plan by which complications develop. It usefully discriminates between metabolic effects of glucose on the target cells showing the complication and the exacerbating effect of independent accelerators, such as arterial hypertension in diabetic nephropathy. Not all independent accelerators have, however, as clearly defined a rela- 


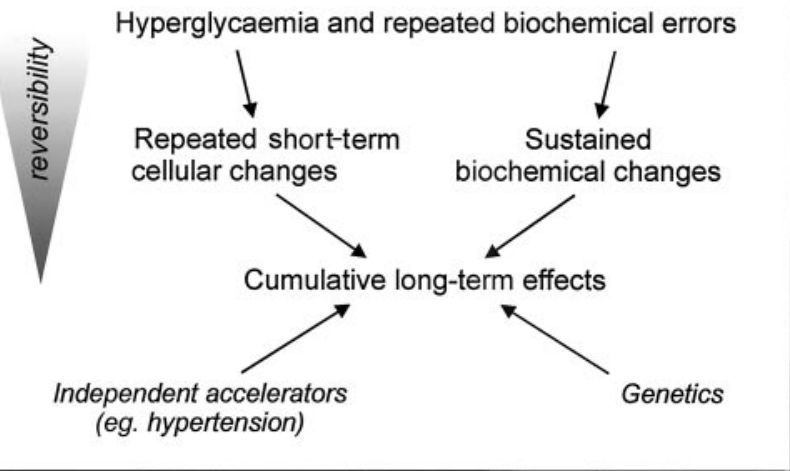

Fig.1. General schematic to indicate pathways for the development of diabetic complications (after Giancarlo Viberti, personal communication). Cellular transducers register the effects of hyperglycaemia and related extracellular biochemical anomalies and convert them to cumulative long-term effects. As short-term biochemical changes translate into long-term effects, with structural anomalies, reversibility is progressively lessened. Independent accelerators (such as arterial hypertension in nephropathy) and genetic predisposition amplify these biochemical effects.

tion with the primary cause of a complication and the nature of this subtlety is important in the design of new drugs aimed at preventing or treating the complication. This will be considered in more detail later.

Explaining the effects of glucose requires identification of the mechanisms by which it disrupts cellular metabolism. A few hypotheses have emerged to explain the initial steps in the effects of glucose. The most clearly defined are the sorbitol hypothesis [5-7] and non-enzymatic glycation of proteins [8-10]. These detailed sources indicate that both metabolic anomalies can contribute to the development of diabetic complications and that they overlap with each other and with other diabetic anomalies. For example, oxidative stress clearly interacts with both the sorbitol pathway [11-13] and non-enzymatic glycation [14-16]. Indeed, it is clear that oxidation of glucose opens up alternative pathways for protein glycation and could, therefore, increase its range and extent, with an amplification of the consequences [14, 17-19]. It is, therefore, important to establish which components of superficially separate metabolic anomalies interact and synergise and by what mechanisms. The literature on the various phenomena which stem from hyperglycaemia, osmotic stress, oxidative stress, glycation and so forth, reveals a recurring topic, namely mitogen-activated protein kinases.

\section{Mitogen-activated protein (MAP) kinases}

Having introduced the potential involvement of MAP kinases in responses to diabetes-derived cellular changes, it is necessary to consider their biochem- istry, classification and nomenclature. Mitogen-activated protein kinases form a group of serine/threonine specific kinases which are activated in response to extracellular stimuli through dual phosphorylation at conserved threonine and tyrosine residues. There are three main groups of MAP kinases; the extracellular signal regulated kinases (ERK), the c-Jun N-terminal kinases (JNK) and the p38 kinases. Although ERK, JNK and p38 are frequently referred to as single entities, the terms refer to homologous groups of kinases with similar activation profiles and substrates. Thus, ERK and JNK have three sub-forms (coded 1, 2 and 3), each set of sub-forms derived from three genes. For JNK, each sub-form has multiple isoforms; four for JNK1, four for JNK2 and two for JNK3 [20]. Thus far, four sub-types have been cloned for $\mathrm{p} 38 ; \alpha, \beta, \gamma, \delta[21]$.

The mechanics of MAP kinase signalling are covered by several recent reviews with details of triggering stimuli and substrates [20,22-24]. Their perceived roles in cell physiology are evolving, but in general p38 is viewed as an osmotic response element [25], JNKs respond to several forms of cellular stress and have become the archetypal stress-activated protein kinases (SAP kinase) [20] and ERKs are primarily regarded as growth factor signalling kinases [22]. It subsequently became clear, however, that both the ERK and p38 kinase groups also respond to cellular stressors (for examples, see [26-29]), so all three MAP kinase groups could turn out to be SAP kinases under certain conditions. The p38 osmotic stress response discussed below is typical of one type of MAP kinase stress response, in that the external stimulus causes adjustments of gene transcription which alter the cellular phenotype. As is described below, the p38 kinase signalling pathway is not responsible for all of the cellular responses to osmotic stress and possibly it could be discovered that the other MAP kinases act in concert to produce the full range of cellular adaptation [30]. Other MAP kinase-initiated responses involve a shift in cell cycle to favour proliferation. Such responses have been extensively studied in oncology [31-33].

\section{Sorbitol pathway}

In diabetes glucose is the principal sorbitol pathway substrate and it is converted to sorbitol by the enzyme aldose reductase, with oxidation of NADPH, followed by oxidation of the sorbitol to fructose by sorbitol dehydrogenase, with reduction of $\mathrm{NAD}^{+}$. Under physiological conditions the pathway also uses glucose and it functions to produce uncharged intracellular osmolytes, as follows.

Renal tubular cells at the medullary extremity of the loop of Henlé are bathed in hypertonic interstitial fluid and the tubular cell compensates for this osmot- 
ic stress by producing sorbitol from glucose by aldose reductase [34]. Exposure of kidney cells in culture to increments in tonicity of their culture medium stimulates transcription of the mRNA for aldose reductase; with increased enzyme activity and sorbitol accumulation this increased transcription is arrested, attaining a new steady state appropriate to the extracellular osmolality [35]. Other molecules also contribute, in particular myo-inositol, betaine and glycerophosphorylcholine and the amino acids taurine and aspartate could also be increased intracellularly on exposure to hypertonic extracellular fluid [36-38]. This phenomenon is not restricted to kidney cells, similar changes in vitro are seen in lens epithelium [39] and the retinal pigment epithelium [37]. It is, therefore, probable that the capacity to increase aldose reductase expression and produce graded amounts of sorbitol in response to hypertonicity is a conserved and a fundamental property of nucleated cells. The identity of the "osmosensor" which initiates this cellular reflex is a mystery, but is considered later.

The involvement of the sorbitol pathway in diabetes is not as simple as the above account might imply. Under certain conditions the pathway could be driven by both osmotic stress and exaggerated concentrations of substrate; raised intracellular glucose resulting from exposure to hyperglycaemia of cells whose glucose uptake is independent of insulin. There is coincidence between insulin-independent glucose uptake and susceptibility to complications [7]. Thus, the situation that pertains in the lens probably exemplifies its most extreme manifestation in diabetes. In diabetes the lens can contain extremely high concentrations of glucose, to which the lenticular epithelium (the site of aldose reductase) is permeable. This is associated with accumulation of sorbitol, which leaks out into the aqueous and vitreous, contributing to an osmotic stress of the lenticular epithelium and increasing expression of aldose reductase [40, 41]. Thus, these combined influences induce aldose reductase and drive a large flux of substrate through its pathway. The extent of osmotically driven aldose reductase expression will vary in other tissues but this will be augmented by raised intracellular glucose, where present. Under these conditions, the cell is forced to produce sorbitol in excess of that required to buffer extracellular tonicity, producing an intracellular osmotic stress. That this occurs is shown by such tissues reducing their content of myo-inositol, by reducing expression of its carrier protein [42, 43]. This must compensate for the intracellular stress imposed by the accumulated sorbitol but it is not possible to judge the efficacy of this compensation. The signalling mechanisms for these processes are being explained by analogy with yeast and by studies on renal mechanisms.

Yeast (Saccharomyces cerevisiae) responds to osmotic stress by autophosphorylation of at least two cell-surface osmosensors. These then activate a signal cascade upstream of a MAP kinase called HOG1 (high osmolarity glycerol) which, as the name implies, results in reduction of glycerol-3-phosphate to produce glycerol as an intracellular osmolyte [44-46]. This sequence of events is analogous to activation of a mammalian MAP kinase, known as p38, though the mammalian osmosensors have not been characterised. Osmotic challenge of kidney cells induces p38 with follow-on activation of immediate early genes. These almost certainly include some of the transcription-dependent osmoprotective events triggered by hypertonicity [47] but this pathway does not appear to induce aldose reductase [48]. It is likely, therefore, that osmotic stress can activate more than one MAP kinase in susceptible tissues. The extent to which osmotic stress participates in the pathophysiology of diabetes will vary with control of glycaemia. It is, however, equally possible that intracellular osmotic stress, as defined above, is also capable of activating MAP kinases and such an event is likely to occur wherever depletion of myo-inositol is associated with sorbitol accumulation in nerve $[49,50]$, kidney $[51,52]$ and retina [53-55]. Differential examination of the influences of dehydration and glucose in the kidney shows different pathways signalling the two stimuli $[56,57]$; this could imply differential activation of multiple MAP kinases.

\section{Non-enzymatic glycosylation of proteins and receptors for advanced glycosylation end-products (RAGE)}

It is clear that there are two generic mechanisms by which non-enzymatic glycation of proteins can cause dysfunction. Firstly, the process changes the protein so that its function within its own domain is altered. Examples are altered physical properties of longlived extracellular proteins forming connective tissues [58] and basal lamina [59, 60], alteration of intracellular structural proteins $[61,62]$ and compromise of intercellular communication [63]. These can also be modified by short-term Amadori reactions or by long-term advanced glycation products with crosslinking. The second generic outcome involves nonenzymatic glycation of circulating proteins, which then interact with cell surface receptors, RAGEs. These receptors probably exist to facilitate the uptake and clearance of these glycosylated proteins but when stimulated to excess, they can mediate adverse cellular events. Recently it has been shown that ligand binding to RAGE activates MAP kinases [15, 64, 65]. The responses downstream of MAP kinase activation by RAGE have yet to be identified but earlier considerations suggest a phenotypic shift or proliferation. 


\section{Oxidative stress}

The notion that oxidative stress participates in the development of diabetic complications dates back over 20 years [66]. Detailed chemistry of interactions between oxidatively derived radicals and tissue components is reviewed elsewhere [67-70]. Plasma lipid peroxides signal oxidative stress [71-73] and this could represent a forerunner of atherosclerosis but it is intracellular oxidative stress that contributes to changes in the cells participating in neuropathy, nephropathy and retinopathy. Furthermore, the oxidation of glucose and the production of reactive intermediates, which interact with intracellular proteins, could well provide a powerful input to the early development of these complications $[18,74]$.

Pragmatically, there are many studies in diabetic rats showing that treatment with antioxidants attenuates or prevents the development of abnormalities of biochemistry or function that are relevant to compli-

Fig. 2 A-D. Activation (phosphorylation) of ERK and JNK in dorsal root ganglia of diabetic rats, plus effects of treatment with a diester of $\gamma$-linolenic and $\alpha$-lipoic acids (GLA-LA; $200 \mathrm{mg} \cdot \mathrm{kg}^{-1} \cdot$ day $^{-1}$ p.o.). Streptozotocin-diabetic rats were either untreated or treated as described above for 8 weeks. Dorsal root ganglia were removed bilaterally at $\mathrm{L}_{4}$ and $\mathrm{L}_{5}$, pooled and processed for western blotting exactly as described elsewhere [102]. Each lane contains protein from the four ganglia from a single rat. Blots (A, ERK and $\mathbf{B}, \mathrm{JNK}$ ) were exposed to antibodies generated against non-phosphorylated epitopes of ERK ("full-length") and JNK (not shown), which revealed no differences between treatments. Exposure to antibodies against phosphorylated epitopes showed considerable activation in untreated diabetic rats (lanes 5 to 8 and bar charts, $(\mathbf{C}$, ERK and $\mathbf{D}, \mathrm{JNK}$ ) in which phospho-reactivity is normalised to non-phospho-reactivity to correct for any variation in total protein content). Treatment with GLA-LA attenuated ERK activation (A and $\mathbf{C}$ ), but enhanced activation of JNK (B and D)by diabetes. For all methods and sources see [102]; $* p<0.05, * * p<0.01$ vs untreated controls cations (for early examples, see [75-80]). In patients, there are fewer studies with traditional antioxidants $[78,81,82]$ but it is probable that the beneficial effects of $\alpha$-lipoic acid [83-85] derive from its antioxidant properties.

There is a large and accumulating literature linking cellular oxidative stress with activation of MAP kinases [27, 86-92]. Although none of this work has been done in diabetes, the markers of oxidative stress are similar in diabetes to those associated with the forms of pro-oxidant treatment used in the studies referred to above.

In general, this work is descriptive and cumulative, in that each new study seems to increase complexity, rather than reveal patterns. Some clarity is, however, evident. Those oxidative stresses that decrease intracellular reduced glutathione (GSH) activate ERK, rather than JNK or p38, at least in fibroblasts [88]. Decreased concentrations of GSH are a consequence of increased flux through the polyol pathway in diabetes $[12,93,94]$, probably because aldose reductase competes with glutathione reductase for NADPH. Thus, there is a possible link between the sorbitol pathway, oxidative stress and ERK activation, which could explain the activation of ERK seen in nervous tissue in diabetic rats (Fig. 2). Other apparent patterns conflict, though it is likely that different cell types have different responses. Thus, hydrogen peroxide activated all three MAP kinases (ERK, JNK, p38) in neonatal ventricular myocytes [90] and in several other cell types [27]. It also activated p38 (the other MAP kinases were not studied) in endothelial cells [87], but in mouse fibroblasts JNK was completely refractory to hydrogen peroxide [95]. As the high concentrations of hydrogen peroxide used in these studies are primarily of value for proof of principle, we now need a systematic examination of the effects of realistic oxidative stress to explain its influence on MAP kinases in diabetes.
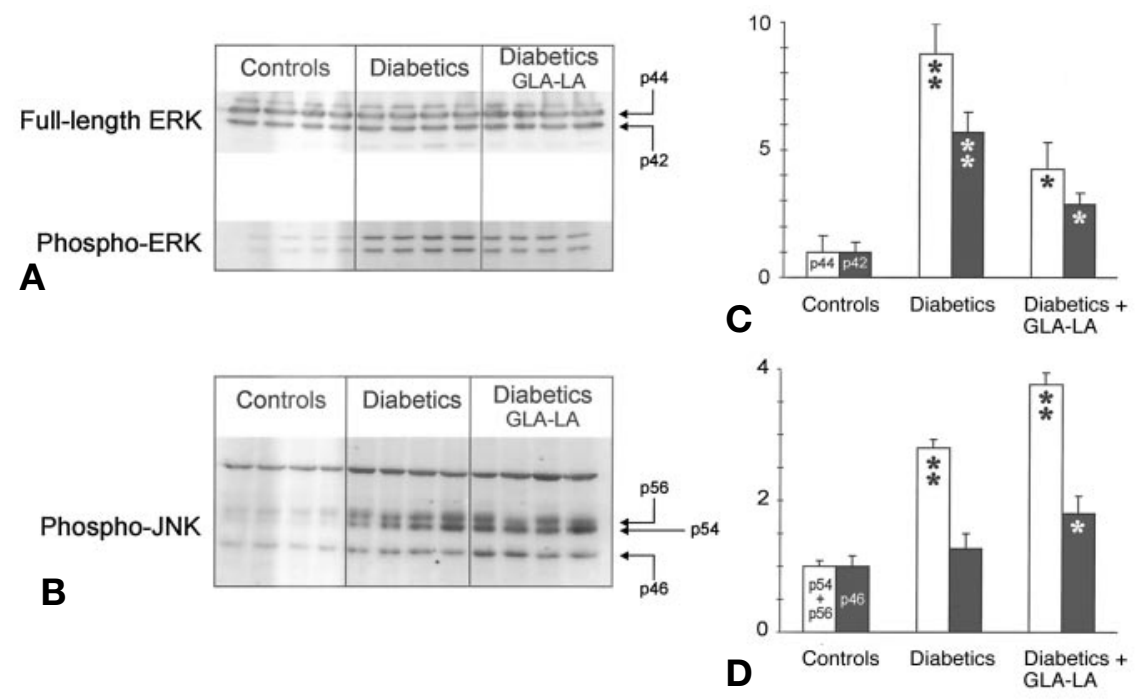
An alternative approach, perhaps with even more value, will come from examination of the influence of various antioxidants on MAP kinase activation both in the presence of specific pro-oxidants and in diabetes. This approach also brings another dimension to this analysis. Activation of MAP kinases in cellular stress possibly forms part of the chain of damage inflicted on the cell by this stress or they could form part of the protective response of the cell. Clearly, the examples considered earlier in the context of osmotic stress illustrate MAP kinase responses in the latter category but when activated by oxidative stress, their identity as criminal or policeman is much less clear. One study shows the complexity of this issue. HeLa or Hep G2 cells treated with butylated hydroxyanisole (BHA), which generates intracellular hydrogen peroxide, show brisk activation of ERK2, followed by a slower activation of JNK1. Pretreatment with antioxidants ( $N$-acetyl-L-cysteine, glutathione or vitamin E) attenuated the ERK2 response but not JNK1 activation [89]. This suggests that ERK activation forms an early component of the damaging effect of oxidative stress, whereas JNK activation could form part of a protective cellular response. These possibilities receive support from experiments on diabetic rats in the author's laboratory (Fig. 2). Dorsal root ganglia from rats with streptozotocin-induced diabetes show strong steady-sate activation of both ERK and JNK ([96] and Fig.2). In rats treated throughout their diabetes with a diester of $\alpha$-lipoic acid and $\gamma$-linolenic acid (GLA-LA), which has antioxidant properties, the ERK response was considerably attenuated but the JNK response was greatly enhanced. As GLA-LA is protective against a number of functional and biochemical defects in diabetic rats [97], these observations support the hypothesis that JNK activation is protective, with the exaggerated activation indicating increased antioxidant protection. The role of ERK remains ambiguous, in that reduction of its activation by an antioxidant could imply that phospho-ERK is damaging but it could also imply that it is a sensitive protective element and that its reduced activation shows the attenuated oxidative stress associated with the antioxidant treatment.

\section{Protein kinase C}

It was reported 10 years ago that exposure of renal glomeruli [98] or endothelial cells [99] to high glucose activates protein kinase $\mathrm{C}(\mathrm{PKC})$. These observations were refined to show activation of multiple sub-types of $\mathrm{PKC}$ in retina of diabetic rats, together with raised concentrations of diacylglycerol; these changes were restored to normal by insulin treatment [100]. The mechanism linking raised glucose to PKC activation could involve oxidative stress because treatment with either vitamin $\mathrm{E}$ or probucol prevents activation [101] and associated retinal hyperaemia [102]. The important link between these phenomena in retinal vasculature and the proliferative phase of retinopathy came with the finding that the activated PKC is involved in the generation of vascular endothelial growth factor (VEGF) [103].

The next important step in the development of understanding of these processes in the kidney came with the observation that calphostin C, a PKC inhibitor, prevented activation of MAP kinase and phospholipase $\mathrm{A}_{2}$ in mesangial cells cultured in high glucose [104]. The polyol pathway was also tied into these phenomena with the observation that an aldose reductase inhibitor prevented the activation of phospholipase $A_{2}$ in glomeruli from diabetic rats [105]. More directly still, an aldose reductase inhibitor was shown to inhibit the activation of PKC and the increase in transforming growth factor $\beta$ (TGF $\beta$ ) production in human mesangial cells cultured in high glucose [106].

The co-activation of PKC and MAP kinases in vascular cells maintained in high glucose [107] reinforces the notion that the two are linked. There is a growing literature outside of diabetes research showing that PKC can activate MAP kinases and that PKC inhibitors can prevent their activation by a range of stimuli (see, for example, [108]) [33, 90]. Thus, the observations cited above suggest that, in vascular tissue, activation of PKC (possibly amplified by increases in its expression) occurs in diabetes by oxidative stress and exaggerated flux through the polyol pathway. Protein kinase $\mathrm{C}$ and diacylglycerol provide haemodynamic abnormalities by impairment of prostanoid and nitric oxide production. The production of VEGF is stimulated synergistically by activated PKC and hypoxia derived from the haemodynamic disturbance. Increased TGF $\beta$ provokes increased synthesis of extracellular matrix materials. The activation of MAP kinases by PKC - as well as through the other pathways described earlier - is implicated in the transcription-dependent changes and phenotypic switches underlying these and probably other undisclosed phenomena. These considerations support the exploration of the potential benefits of a selective inhibitor of PKC sub-forms as agents targeted at diabetic retinopathy [109].

\section{Diabetic neuropathy}

It should be emphasised that the changes referred to above are vascular in origin and could well be central to the abnormalities associated with nephropathy and retinopathy. It is in these tissues where altered production and glycosylation of extracellular matrix have a profound effect and where microvascular pathology is instrumental in the development of dys- 
function. In peripheral nervous tissue of diabetic rats there is no evidence of steady-state activation of any of the sub-forms of PKC [110-113]. This indicates that there are fundamental differences in the transduction of glucose effects in nervous tissue from those in retina and kidney. There are those who have argued for vascular causation of neuropathy through endoneurial ischaemia of peripheral nerve trunks [114-116]. It is, however, difficult to reconcile such a simple hypothesis with a condition in which sensory defects can be present without symptomatic problems in motor fibres of the same trunk [117]. Of course, overwhelming evidence implicates vascular dysfunction in the development, or maturation of neuropathy in diabetes, but nerve ischaemia might more accurately be viewed as an accelerator (Fig. 1), than as a primary cause. Earlier metabolic changes in diabetes make nerves more susceptible to ischaemic damage [118]. Thus, we must identify the glucose transducer in peripheral nerve and find phenomena which bias the damaging effect of glucose towards sensory fibres.

Neurones are terminally differentiated, so that the MAP kinases do not subserve transcriptional changes associated with proliferation; instead they communicate signals which adjust neuronal phenotype [119, 120]. Nevertheless, a large amount of work in this area has used PC12 cells. These are a rat pheochromocytoma cell line and do proliferate, so that not all findings extrapolate to adult neurones in vivo, and it is this phenotype that enters the pathway to damage in diabetes. Mitogen-activated protein kinases are involved in the signalling cascade activated by neurotrophic factors [121, 122] and, because neurotrophins have effects on developing nerves which differ considerably from those on adult neurones, there is need for further caution in extrapolation. Some facts, however, are clear.

Mitogen-activated protein kinases are activated downstream of a cascade initiated by phosphorylation of the tyrosine kinase domains of the neurotrophin tyrosine kinase receptors, which proceeds through adaptor proteins and small GTP-binding proteins of the Ras family, phosphorylating Raf and activating the MAP kinase module [108, 123]. Extracellular signal regulated kinase is the end-stage MAP kinase in this cascade and it phosphorylates both nuclear and cytoplasmic substrates.

In neurones JNK is activated by a variety of stimuli, including growth factors, trophic factors, cytokines, ultraviolet light and HIV-1 [124-126]. There is little evidence of activation of $\mathrm{p} 38$ in neurones and certainly no indication of stress-induced phosphorylation of this kinase. Activation of JNK and ERK by growth/ trophic factors appears to be differential, both with respect to the activating stimuli and the involvement of the Ras GTP binding proteins [124]. Nerve growth factor (NGF) is capable of activating both ERK and
JNK under different conditions and with different results. Nerve growth factor interacts with two different receptors in neurones as part of its physiological action; these are the high-affinity tyrosine kinase receptor, trkA, and the low-affinity receptor, p $75^{\mathrm{NTR}}$. Where these receptors act in concert, the signalling pathway described above through ERK predominates and the NGF-supported phenotype is maintained, for example in non-myelinated nociceptors [127-129]. A different picture emerges when the p75 neurotrophin receptor is present without trkA, because under these conditions NGF activates JNK and cell death can be a consequence [130,131]. Introduction of trkA removes the link to cell death [132].

Not surprisingly, these considerations have led to the view that, whereas ERK appears to exert a role in the normal physiological signalling of healthy neurones, JNK has some sinister role. In sensory nerves of diabetic rats both are activated (Fig.2 and [96]) but the extent to which this happens in human nervous tissue in diabetes is still to be shown. The consequences of persistent activation of MAP kinases in diabetes are also unknown as yet, though some speculations are possible. Firstly, the consequences possibly differentiate between different classes of neurone, because ERK is strikingly absent from the cell bodies of motor neurones [96]. Accordingly an involvement in dysfunction could explain the predisposition of diabetic neuropathy for sensory fibres. Secondly, persistent high-level activation of ERK could make the transcription factors that are its normal substrate, when activated by neurotrophin trk receptors, refractory to neurotrophin stimulation. This is speculative, but some conflict is certainly possible and part of the signalling process for NGF requires its capture, internalisation and retrograde axonal transport to the neuronal cell body, processes which are impaired in diabetes $[133,134]$. It is impossible to reconcile the reduced concentrations of NGF available to peripheral neurones in diabetic rats [135] and the impaired receptor function $[136,137]$ with any assumption that ERK is activated only as part of the NGF signalling cascade. Clearly, in diabetic rats, ERK activation in neurones is driven by something other than neurotrophins; but it is not driven by insulin, which, along with NGF, was the first physiological ERK activator to be identified [138].

We do not know what transcription signals are altered by the persistently activated ERK in diabetes; indeed it could be that persistent activation of a signal that might normally be pulsatile could render downstream processes refractory. There is good evidence that the persistent activation of JNK causes phosphorylation of inappropriate substrates, in particular non-nuclear substrates such as neurofilaments, where it could be the direct cause of hyperphosphorylation [96]. Hyperphosphorylation of neurofilaments is associated with filamentous tangles, axodendritic swell- 


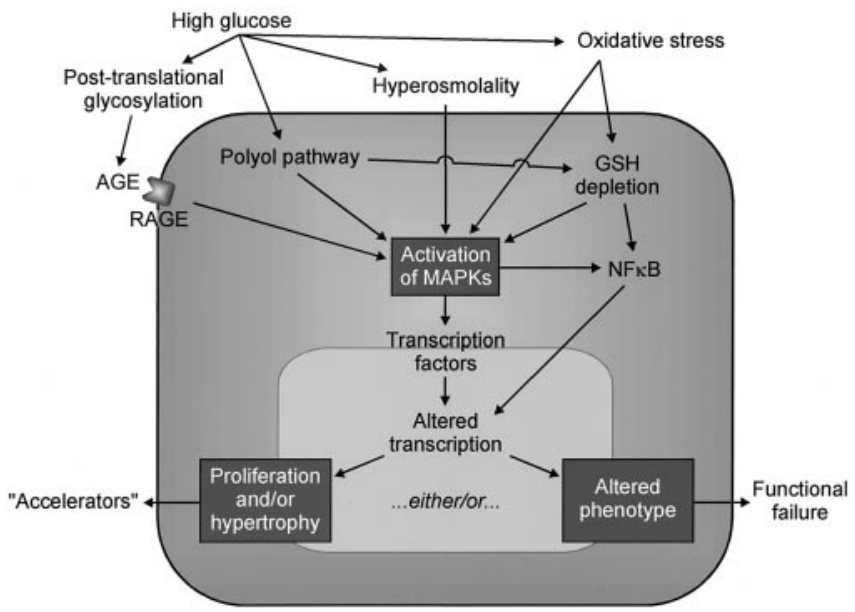

Fig. 3. Synopsis of the hypotheses advanced in this review. Hyperglycaemia exerts several influences on cells, which can synergise by activation of mitogen-activated protein kinases (MAPKs). By adjustment of activation of transcription factors, these can alter the balance of gene expression, leading to a spectrum of changes from cellular proliferation, altered production of extracellular materials or a dysfunctional change in phenotype. NFxB, nuclear factor kappa B

ing and neurodegeneration associated and is present in a range of diseases, including human diabetic neuropathy $[139,140]$. It is, therefore, possible that JNK activation could be pathogenic through neurofilament phosphorylation in several disease states. Obviously, it is difficult to reconcile these speculations with the finding that a drug with many beneficial effects in diabetic rats [97] appears to amplify activation of a MAP kinase that could be damaging. Our understanding of these phenomena is in its infancy. What little we do understand, as covered by this review, is summarised in Figure 3.

\section{Drug targets?}

The final consideration is the possibility that these MAP kinases could serve as useful targets for novel drugs targeted at diabetic complications. The first reaction is that they are too ubiquitous in both distribution and function so that modulation would have too many side effects. The notion that an antagonist of PKC could have therapeutic value might, however, have been ridiculed 10 years ago, whereas the development of understanding of different sub-forms of $\mathrm{PKC}$ has produced a selective antagonist that is now in clinical trial for retinopathy. Figure 4 illustrates the problems of developing new drugs against complications, a venture that has not been strikingly successful. The extreme refinement of drug action, as exemplified by nerve growth factor, gives an agent whose targets are restricted to a sub-population of affected neurones in diabetic neuropathy. Such an

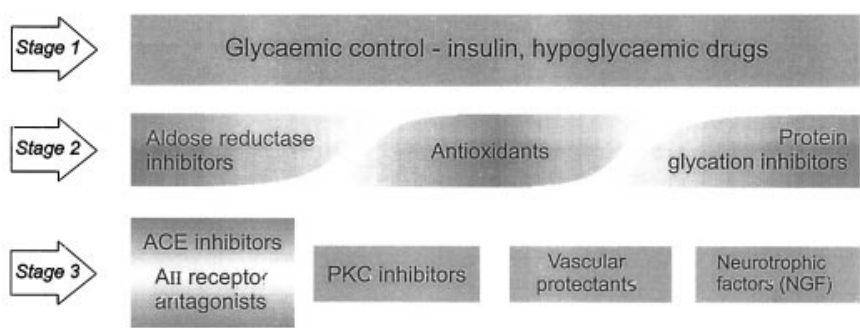

Fig. 4. Schematic illustrating pharmacological defence against glucose and the causation of diabetic complications. This can be considered in three stages, with Stage 1 represented by protection of all tissues against hyperglycaemia; inevitably this will fail at times. Stage 2 indicates protection by removal of a relatively specific biochemical abnormality and the shaded edges of these compartments indicates the overlap referred to in the text. It is implicit that Stage 2 will protect more than one tissue/organ. In Stage 3, targeting is more specific for individual complications or even, as exemplified by nerve growth factor (NGF), a sub-division of the peripheral nervous system. A breach of the protection offered by insulin requires a second line of defence against a range of insults and, so far, no single drug gives such comprehensive cover. A clinical trial of any single agent in Stage 2 (antioxidants, aldose reductase inhibitors, anti-glycation agents) will leave large gaps in the Stage 2 defences, which could prejudice trial outcomes

agent might have been useful as part of a battery of drugs, though in isolation it was not possible to show any efficacy and clinical development has ceased. In contrast, angiotensin converting enzyme inhibitors have been successful in slowing the progression of nephropathy because they control a major independent accelerator of the complication. Nevertheless, Figure 4 makes it clear that an ideal agent will have a broad spectrum of action. The potential involvement of MAP kinases in the full range of actions of glucose against all of the tissues responsible for the late complications of diabetes suggests that they should be given serious consideration as drug targets.

Acknowledgements. This review is based on the Golgi lecture delivered to the EASD in Barcelona in September 1998. I am grateful to Professor John Ward for his nomination, to the EASD for their award of the Castelli Pedroli Prize and to the Foundation for underwriting the award. I am grateful to all my collaborators, especially Paul Fernyhough, for reducing my ignorance and to the research funding bodies - especially the British Diabetic Association. I thank Luke Hounsom for permission to use the data shown in Figure 2.

\section{References}

1. Diabetes Control and Complications Trial Research Group (1993) The effect of intensive treatment of diabetes on the development and progression of long-term complications in insulin-dependent diabetes mellitus. $\mathrm{N}$ Eng J Med 329: 977-986

2. Pirart J (1977) Diabete et complictions degeneratives presentation d'une etude prospective portant sur 4400 cas observes entre 1949-1973. Diabetes Metab 3: 97-107 
3. Pirart J (1978) Diabetes mellitus and its degenerative complications: a prospective study of 4400 patients observed between 1947 and 1973. Part 2. Diabetes Care 1: 252-263

4. Pirart J (1978) Diabetes mellitus and its degenerative complications; a prospective study of 4400 patients observed between 1947 and 1973. Part 1. Diabetes Care 1: 168-188

5. Yabe-Nishimura C (1998) Aldose reductase in glucose toxicity: A potential target for the prevention of diabetic complications. Pharmacological Reviews 50: 21-33

6. Tomlinson DR (1993) Aldose reductase inhibitors and the complications of diabetes mellitus. Diabet Med 10: 214-230

7. Dvornik D (1987) Aldose reductase inhibition. Biomedical Information Corporation McGraw-Hill, New York

8. Hamada Y, Araki N, Koh N, Nakamura J, Horiuchi S, Hotta N (1996) Rapid formation of advanced glycation end products by intermediate metabolites of glycolytic pathway and polyol pathway. Biochem Biophys Res Commun 228: 539-543

9. Brownlee M (1995) The pathological implications of protein glycation. Clin Invest Med 18: 275-281

10. McCance DR, Dyer DG, Dunn JA et al. (1993) Maillard reaction products and their relation to complications in insulin-dependent diabetes mellitus. J Clin Invest 91: 2470-2478

11. Rittner HL, Hafner V, Klimiuk PA, Szweda LI, Goronzy JJ, Weyand CM (1999) Aldose reductase functions as a detoxification system for lipid peroxidation products in vasculitis. J Clin Invest 103: 1007-1013

12. Bravi MC, Pietrangeli P, Laurenti O et al. (1997) Polyol pathway activation and glutathione redox status in noninsulin-dependent diabetic patients. Metabolism 46: 1194-1198

13. Phillips SA, Mirrlees D, Thornalley PJ (1993) Modification of the glyoxalase system in streptozotocin- induced diabetic rats. Effect of the aldose reductase inhibitor Statil. Biochem Pharmacol 46: 805-811

14. Galle J, Schneider R, Winner B et al. (1998) Glyc-oxidized LDL impair endothelial function more potently than oxidized LDL: role of enhanced oxidative stress. Atherosclerosis 138: 65-77

15. Lander HM, Tauras JM, Ogiste JS, Hori O, Moss RA, Schmidt AM (1997) Activation of the receptor for advanced glycation end products triggers a p $21^{\text {ras }}$-dependent mitogen-activated protein kinase pathway regulated by oxidant stress. J Biol Chem 272: 17810-17814

16. Soulis-Liparota T, Cooper ME, Dunlop M, Jerums G (1995) The relative roles of advanced glycation, oxidation and aldose reductase inhibition in the development of experimental diabetic nephropathy in the Sprague-Dawley rat. Diabetologia 38: 387-394

17. Baker JR, Zyzak DV, Thorpe SR, Baynes JW (1994) Chemistry of the fructosamine assay: D-glucosone is the product of oxidation of Amadori compounds. Clin Chem 40: $1950-1955$

18. Fu MX, Wells-Knecht KJ, Blackledge JA, Lyons TJ, Thorpe SR, Baynes JW (1994) Glycation, glycoxidation, and cross-linking of collagen by glucose. Kinetics, mechanisms, and inhibition of late stages of the Maillard reaction. Diabetes 43: 676-683

19. Le Guen CA, Jones AF, Barnett AH, Lunec J (1992) Role of reactive oxygen species in the generation of fluorescence by glycation. Ann Clin Biochem 29: 184-189

20. Ip YT, Davis RJ (1998) Signal transduction by the c-Jun N-terminal kinase (JNK) - from inflammation to development. Curr Opin Cell Biol 10: 205-219
21. Wang XS, Diener K, Manthey CL et al. (1997) Molecular cloning and characterization of a novel p38 mitogen-activated protein kinase. J Biol Chem 272: 23668-23674

22. Davis RJ (1995) Transcriptional regulation by MAP kinases. Mol Reprod Dev 42: 459-467

23. Su B, Karin M (1996) Mitogen-activated protein kinase cascades and regulation of gene expression. Curr Opin Immunol 8: 402-411

24. Garrington TP, Johnson GL (1999) Organization and regulation of mitogen-activated protein kinase signaling pathways. Curr Opin Cell Biol 11: 211-218

25. Han J, Lee JD, Bibbs L, Ulevitch RJ (1994) A MAP kinase targeted by endotoxin and hyperosmolarity in mammalian cells. Science 265: 808-811

26. Raingeaud J, Gupta S, Rogers JS et al. (1995) Pro-inflammatory cytokines and environmental stress cause p38 mitogen-activated protein kinase activation by dual phosphorylation on tyrosine and threonine. J Biol Chem 270: $7420-7426$

27. Guyton KZ, Liu Y, Gorospe M, Xu Q, Holbrook NJ (1996) Activation of mitogen-activated protein kinase by $\mathrm{H} 2 \mathrm{O} 2$. Role in cell survival following oxidant injury. J Biol Chem 271: 4138-4142

28. Liu Y, Guyton KZ, Gorospe M, Xu Q, Lee JC, Holbrook NJ (1996) Differential activation of ERK, JNK/SAPK and P38/CSBP/RK map kinase family members during the cellular response to arsenite. Free Radic Biol Med 21: 771-781

29. Price MA, Cruzalegui FH, Treisman R (1996) The p38 and ERK MAP kinase pathways cooperate to activate Ternary Complex Factors and c-fos transcription in response to UV light. EMBO J 15: 6552-6563

30. Berl T, Siriwardana G, Ao L, Butterfield LM, Heasley LE (1997) Multiple mitogen-activated protein kinases are regulated by hyperosmolality in mouse IMCD cells. Am J Physiol 272: F305-F311

31. Cowley S, Paterson H, Kemp P, Marshall CJ (1994) Activation of MAP kinase kinase is necessary and sufficient for PC12 differentiation and for transformation of $\mathrm{NIH}$ 3T3 cells. Cell 77: 841-852

32. Lu G, Beuerman RW, Zhao S et al. (1997) Tumor necrosis factor-alpha and interleukin-1 induce activation of MAP kinase and SAP kinase in human neuroma fibroblasts. Neurochem Int 30: 401-410

33. Dent P, Jarvis WD, Birrer MJ, Fisher PB, Schmidt-Ullrich RK, Grant S (1998) The roles of signaling by the p42/ p44 mitogen-activated protein (MAP) kinase pathway; a potential route to radio- and chemo-sensitization of tumor cells resulting in the induction of apoptosis and loss of clonogenicity. Leukemia 12: 1843-1850

34. Bagnasco SM, Balaban R, Fales HM, Yang Y-M, Burg M (1986) Predominant osmotically active solutes in rat and rabbit renal medullas. J Biol Chem 261: 5872-5877

35. Smardo FL, Jr., Burg MB, Garcia-Perez A (1992) Kidney aldose reductase gene transcription is osmotically regulated. Am J Physiol 262:C776-C782

36. Edmands S, Yancey PH (1992) Effects on rat renal osmolytes of extended treatment with an aldose reductase inhibitor. Comp Biochem Physiol C103: 499-502

37. Lin L-R, Carper D, Yokoyama T, Reddy VN (1993) The effect of hypertonicity on aldose reductase, al$\mathrm{pha}_{\mathrm{B}}$-crystallin, and organic osmolytes in the retinal pigment epithelium. Invest Ophthalmol Vis Sci 34: 23522359

38. Stevens MJ, Lattimer SA, Kamijo M, Van Huysen C, Sima AAF, Greene DA (1993) Osmotically-induced nerve taurine depletion and the compatible osmolyte hypothesis in 
experimental diabetic neuropathy in the rat. Diabetologia 36: 608-614

39. Bondy CA, Lightman SL (1989) Developmental and physiological pattern of aldose reductase mRNA expression in lens and retina. Mol Endocrinol 3: 1417-1425

40. Iwata T, Sato S, Jimenez J et al. (1999) Osmotic response element is required for the induction of aldose reductase by tumor necrosis factor-a. J Biol Chem 274: 7993-8001

41. Xiong H, Cheng HM (1989) Aqueous/vitreous tonicity in "sugar" cataracts. Ophthalmic Res 21: 292-296

42. Burger-Kentischer A, Müller E, Neuhofer W, März J, Thurau K, Beck FX (1998) Expression of $\mathrm{Na}^{+} / \mathrm{Cl}^{-} /$betaine and $\mathrm{Na}^{+}$/myo-inositol transporters, aldose reductase and sorbitol dehydrogenase in macula densa cells of the kidney. Pflugers Arch 436: 807-809

43. Burger-Kentischer A, Müller E, Neuhofer W, März J, Thurau K, Beck FX (1999) Expression of aldose reductase, sorbitol dehydrogenase and $\mathrm{Na}^{+} /$myo-inositol and $\mathrm{Na}^{+} / \mathrm{Cl}^{-} /$betaine transporter mRNAs in individual cells of the kidney during changes in the diuretic state. Pflugers Arch 437: 248-254

44. Posas F, Wurgler MS, Maeda T, Witten EA, Thai TC, Saito $\mathrm{H}$ (1996) Yeast HOG1 MAP kinase cascade is regulated by a multistep phosphorelay mechanism in the SLN1-YPD1SSK1 "two-component" osmosensor. Cell 86: 865-875

45. Maeda T, Takekawa M, Saito H (1995) Activation of yeast PBS2 MAPKK by MAPKKKs or by binding of an SH3containing osmosensor. Science 269: 554-558

46. Maeda T, Wurgler MS, Saito H (1994) A two-component system that regulates an osmosensing MAP kinase cascade in yeast. Nature 369: 242-245

47. Sheikh-Hamad D, Di Mari J, Suki WN, Safirstein R, Watts BA3, Rouse D (1998) p38 kinase activity is essential for osmotic induction of mRNAs for HSP70 and transporter for organic solute betaine in Madin- Darby canine kidney cells. J Biol Chem 273: 1832-1837

48. Kultz D, Garcia-Perez A, Ferraris JD, Burg MB (1997) Distinct regulation of osmoprotective genes in yeast and mammals. Aldose reductase osmotic response element is induced independent of p38 and stress-activated protein kinase/Jun $\mathrm{N}$ - terminal kinase in rabbit kidney cells. J Biol Chem 272: 13165-13170

49. Finegold D, Lattimer SA, Nolle S, Bernstein M, Greene DA (1983) Polyol pathway activity and myo-inositol metabolism. A suggested relationship in the pathogenesis of diabetic neuropathy. Diabetes 32: 988-992

50. Mayer JH, Tomlinson DR (1983) Prevention of defects of axonal transport and nerve conduction velocity by oral administration of myo-inositol or an aldose reductase inhibitor in streptozotocin-diabetic rats. Diabetologia 25: 433-438

51. Cohen MP (1986) Aldose reductase, glomerular metabolism, and diabetic nephropathy. Metabolism 35: 55-59

52. Cohen MP, Klepser H (1988) Glomerular Na + -K + -ATPase activity in acute and chronic diabetes and with aldose reductase inhibition. Diabetes 37: 558-562

53. MacGregor LC, Rosecan LR, Laties AM, Matschinsky FM (1986) Altered Retinal Metabolism in Diabetes I. Microanalysis of lipid, glucose, sorbitol and myo-inositol in the choroid and in the individual layers of the rabbit retina. J Biol Chem 261: 4046-4051

54. Li WY, Zhou Q, Tang L, Qin M, Hu TS (1990) Intramural pericyte degeneration in early diabetic retinopathy study in vitro. Chin Med J (Engl) 103: 7-13

55. Kern TS, Engerman RL (1991) Retinal polyol and myoinositol in galactosemic dogs given an aldose-reductase inhibitor. Invest Ophthalmol Vis Sci 32: 3175-3177
56. Nakanishi T, Uyama O, Sugita M (1991) Osmotically regulated taurine content in rat renal inner medulla. Am J Physiol 261:F957-F962

57. Nakanishi T, Yamauchi A, Sugita M, Takamitsu Y (1996) Aldose reductase and myo-inositol transporter mRNA are independently regulated in rat renal medulla. J Am Soc Nephrol 7: 283-289

58. Yue DK, Delbridge L, Handelsmann DJ, Reeve T, Turtle JR (1983) The thermal stability of collagen in diabetic rats: correlation with severity of diabetes and non-enzymatic glycosylation. Diabetologia 24: 282-285

59. Nicholls K, Mandel TE (1989) Advanced glycosylation end-products in experimental murine diabetic nephropathy: effect of islet isografting and of aminoguanidine. Lab Invest 60: 486-491

60. Ellis EN, Good BH (1991) Prevention of glomerular basement membrane thickening by aminoguanidine in experimental diabetes mellitus. Metabolism 40: 1016-1019

61. McLean WG (1997) The role of the axonal cytoskeleton in diabetic neuropathy. Neurochem Res 22: 951-956

62. Ryle C, Donaghy M (1995) Non-enzymatic glycation of peripheral nerve proteins in human diabetics. J Neurol Sci 129: 62-68

63. Federoff HJ, Lawrence D, Brownlee M (1993) Nonenzymatic glycosylation of laminin and the laminin peptide CIKVAVS inhibits neurite outgrowth. Diabetes 42: 509-513

64. Simm A, Munch G, Seif F et al. (1997) Advanced glycation endproducts stimulate the MAP-kinase pathway in tubulus cell line LLC-PK1. FEBS Lett 410: 481-484

65. Thornalley PJ (1998) Cell activation by glycated proteins. AGE receptors, receptor recognition factors and functional classification of AGEs. Cell Mol Neurobiol 44: 1013-1023

66. Wallace DJ (1977) The biology of aging: 1976, an overview. J Am Geriatr Soc 25: 104-111

67. Van Dam PS, Bravenboer B (1997) Oxidative stress and antioxidant treatment in diabetic neuropathy. Neurosci Res Commun 21: 41-48

68. Packer L, Witt EH, Tritschler HJ (1995) a-Lipoic acid as a biological antioxidant. Free Radic Biol Med 19: 227-250

69. Tesfamariam B (1994) Free radicals in diabetic endothelial cell dysfunction. Free Radic Biol Med 16: 383-391

70. Wolff SP, Jiang ZY, Hunt JV (1991) Protein glycation and oxidative stress in diabetes mellitus and ageing. Free Radic Biol Med 10: 339-352

71. Nishigaki I, Hagihara M, Tsunekawa T, Masaki M, Yagi K (1981) Lipid peroxide level of serum lipoprotein fractions of diabetic patients. Biochem Med 25: 373-378

72. Gallou G, Ruelland A, Legras B, Maugendre D, Allannic H, Cloarec L (1993) Plasma malondialdehyde in type 1 and type 2 diabetic patients. Clin Chim Acta 214: 227-234

73. Lung C, Pinnas JL, Danial Yahya M, Meinke GC, Mooradian AD (1993) Malondialdehyde modified proteins and their antibodies in the plasma of control and streptozotocin induced diabetic rats. Life Sci 52: 329-337

74. Baynes JW (1994) AGEing growth factors: A role in diabetic vascular disease. J Clin Invest 94: 2

75. Ross WM, Creighton MO, Stewart-DeHann PJ, Sanwal M, Hirst M, Trevithick JR (1982) Modelling cortical cataractogenesis. III. In vitro effects of vitamin $\mathrm{E}$ on cataractogenesis in diabetic rats. Can J Ophthalmol 17: 61-66

76. Morel DW, Chisolm GM (1989) Antioxidant treatment of diabetic rats inhibits lipoprotein oxidation and cytotoxicity. J Lipid Res 30: 1827-1834

77. Srivastava SK, Ansari NH, Liu S et al. (1989) The effect of oxidants on biomembranes and cellular metabolism. Mol Cell Biochem 91: 149-157 
78. Kunisaki M, Umeda F, Inoguchi T, Watanabe J, Nawata H (1990) Effect of vitamin E administration on platelet function in diabetes mellitus. Diabetes Res Clin Pract 14: $37-42$

79. Young IS, Torney JJ, Trimble ER (1992) The effect of ascorbate supplementation on oxidative stress in the streptozotocin diabetic rat. Free Radic Biol Med 13: 41-46

80. Cameron NE, Cotter MA, Maxfield EK (1993) Anti-oxidant treatment prevents the development of peripheral nerve dysfunction in streptozotocin-diabetic rats. Diabetologia 36: 299-304

81. Ting HH, Timimi FK, Boles KS, Creager SJ, Ganz P, Creager MA (1996) Vitamin C improves endothelium-dependent vasodilation in patients with non-insulin-dependent diabetes mellitus. J Clin Invest 97: 22-28

82. Rösen P, Du XL, Tschöpe D (1998) Role of oxygen derived radicals for vascular dysfunction in the diabetic heart: Prevention by a-tocopherol? Mol Cell Biochem 188: 103-111

83. Sachse G, Willms B (1980) Efficacy of thioctic acid in the therapy of peripheral diabetic neuropathy. Horm Metab Res Suppl 9: 105-107

84. Ziegler D, Hanefeld M, Ruhnau KJ et al. (1995) Treatment of symptomatic diabetic peripheral neuropathy with the anti-oxidant a-lipoic acid - A 3-week multicentre randomized controlled trial (ALADIN study). Diabetologia 38: 1425-1433

85. Ziegler D, Gries FA (1997) a-lipoic acid in the treatment of diabetic peripheral and cardiac autonomic neuropathy. Diabetes 46:S62-S66

86. Mendelson KG, Contois LR, Tevosian SG, Davis RJ, Paulson KE (1996) Independent regulation of JNK/ p38 mitogen-activated protein kinases by metabolic oxidative stress in the liver. Proc Natl Acad Sci U S A 93: 12908-12913

87. Huot J, Houle F, Marceau F, Landry J (1997) Oxidative stress-induced actin reorganization mediated by the p38 mitogen-activated protein kinase/heat shock protein 27 pathway in vascular endothelial cells. Circ Res 80: 383-392

88. Numazawa S, Yamada H, Furusho A, Nakahara T, Oguro T, Yoshida T (1997) Cooperative induction of c-fos and heme oxygenase gene products under oxidative stress in human fibroblastic cells. Exp Cell Res 237: 434-444

89. Yu R, Tan TH, Kong AT (1997) Butylated hydroxyanisole and its metabolite tert- butylhydroquinone differentially regulate mitogen-activated protein kinases. The role of oxidative stress in the activation of mitogen-activated protein kinases by phenolic antioxidants. J Biol Chem 272: 28962-28970

90. Clerk A, Michael A, Sugden PH (1998) Stimulation of multiple mitogen-activated protein kinase sub- families by oxidative stress and phosphorylation of the small heat shock protein, HSP25/27, in neonatal ventricular myocytes. Biochem J 333: 581-589

91. Kong ANT, Yu R, Lei W, Mandlekar S, Tan TH, Ucker DS (1998) Differential activation of MAPK and ICE/ Ced-3 protease in chemical-induced apoptosis - The role of oxidative stress in the regulation of mitogen-activated protein kinases (MAPKs) leading to gene expression and survival or activation of caspases leading to apoptosis. Restorative Neurol Neurosci 12: 63-70

92. Wang XT, Martindale JL, Liu YS, Holbrook NJ (1998) The cellular response to oxidative stress: influences of mitogen- activated protein kinase signalling pathways on cell survival. Biochem J 333: 291-300
93. Gonzalez A-M, Sochor M, McLean P (1983) The effect of an aldose reductase inhibitor (sorbinil) on the level of metabolites in lenses of diabetic rats. Diabetes 32: 482-485

94. De Mattia G, Laurenti O, Bravi C, Ghiselli A, Iuliano L, Balsano F (1994) Effect of aldose reductase inhibition on glutathione redox status in erythrocytes of diabetic patients. Metabolism 43: 965-968

95. Adler V, Schaffer A, Kim J, Dolan L, Ronai Z (1995) UV irradiation and heat shock mediate JNK activation via alternate pathways. J Biol Chem 270: 26071-26077

96. Fernyhough P, Gallagher A, Averill S, Priestley JV, Hounsom L, Tomlinson DR (1999) Aberrant neurofilament phosphorylation in sensory neurons of rats with diabetic neuropathy. Diabetes 48: 881-889

97. Hounsom L, Horrobin DF, Tritschler H, Corder R, Tomlinson DR (1998) A lipoic acid-gamma linolenic acid congugate is effective against multiple indices of experimental diabetic neuropathy. Diabetologia 41: 839-843

98. Craven PA, De Rubertis FR (1989) Protein kinase C is activated in glomeruli from streptozotocin diabetic rats. Possible mediation by glucose. J Clin Invest 83: 16671675

99. Lee T-S, Saltsman KA, Ohashi H, King GL (1989) Activation of protein kinase $\mathrm{C}$ by elevation of glucose concentration: Proposal for a mechanism in the development of diabetic vascular complications. Proc Natl Acad Sci USA 86: $5141-5145$

100. Shiba T, Inoguchi T, Sportsman JR, Heath WF, Bursell S, King GL (1993) Correlation of diacylglycerol level and protein kinase $\mathrm{C}$ activity in rat retina to retinal circulation. Am J Physiol 265:E783-E793

101. Kunisaki M, Bursell S-E, Umeda F, Nawata H, King GL (1994) Normalization of diacylglycerol-protein kinase C activation by vitamin $\mathrm{E}$ in aorta of diabetic rats and cultured rat smooth muscle cells exposed to elevated glucose levels. Diabetes 43: 1372-1377

102. Kunisaki M, Bursell S-E, Clermont AC et al. (1995) Vitamin $\mathrm{E}$ prevents diabetes-induced abnormal retinal blood flow via the diacylglycerol-protein kinase $\mathrm{C}$ pathway. Am J Physiol 269:E239-E246

103. Doanes AM, Hegland DD, Sethi R, Kovesdi I, Bruder JT, Finkel T (1999) VEGF stimulates MAPK through a pathway that is unique for receptor tyrosine kinases. Biochem Biophys Res Commun 255: 545-548

104. Haneda M, Araki S, Togawa M, Sugimoto T, Isono M, Kikkawa R (1997) Mitogen-activated protein kinase cascade is activated in glomeruli of diabetic rats and glomerular mesangial cells cultured under high glucose conditions. Diabetes 46: 847-853

105. Keogh RJ, Dunlop ME, Larkins RG (1997) Effect of inhibition of aldose reductase on glucose flux, diacylglycerol formation, protein kinase $\mathrm{C}$, and phospholipase $\mathrm{A} 2$ activation. Metabolism 46: 41-47

106. Ishii H, Tada H, Isogai S (1998) An aldose reductase inhibitor prevents glucose-induced increase in transforming growth factor-b and protein kinase $\mathrm{C}$ activity in cultured human mesangial cells. Diabetologia 41: 362-364

107. Haneda M, Kikkawa R, Sugimoto T et al. (1995) Abnormalities in protein kinase $\mathrm{C}$ and MAP kinase cascade in mesangial cells cultured under high glucose conditions. J Diabetes Complications 9: 246-248

108. Wood KW, Sarnecki C, Roberts TM, Blenis J (1992) ras Mediates nerve growth factor receptor modulation of three signal-transducing protein kinases: MAP kinase, Raf- 1, and RSK. Cell 68: 1041-1050

109. Bursell SE, Takagi C, Clermont AC et al. (1997) Specific retinal diacylglycerol and protein kinase $\mathrm{C}$ beta isoform 
modulation mimics abnormal retinal hemodynamics in diabetic rats. Invest Ophthalmol Vis Sci 38: 2711-2720

110. Borghini I, Ania-Lahuerta A, Regazzi R et al. (1994) a, bI, bII, d, and e protein kinase $\mathrm{C}$ isoforms and compound activity in the sciatic nerve of normal and diabetic rats. $\mathbf{J}$ Neurochem 62: 686-696

111. Rowe-Rendleman CL, Eichberg J (1994) P0 phosphorylation in nerves from normal and diabetic rats: Role of protein kinase $\mathrm{C}$ and turnover of phosphate groups. Neurochem Res 19: 1023-1031

112. Mathew J, Bianchi R, McLean WG et al. (1997) Phosphoinositide metabolism, Na,K-ATPase and protein kinase $\mathrm{C}$ are altered in peripheral nerve from Zucker diabetic fatty rats (ZDF/Gmi-fa). Neurosci Res Commun 20: 21-30

113. Roberts RE, McLean WG (1997) Protein kinase C isozyme expression in sciatic nerves and spinal cords of experimentally diabetic rats. Brain Research 754: 147-156

114. Tuck RR, Schmelzer JD, Low PA (1984) Endoneurial blood flow and oxygen tension in the sciatic nerves of rats with experimental diabetic neuropathy. Brain 107: 935-950

115. Dyck PJ, Karnes JL, O'Brien PC, Okazaki H, Lais A, Engelstad JK (1986) The spatial distribution of fiber loss in diabetic polyneuropathy suggests ischemia. Ann Neurol 19: 440-449

116. Cameron NE, Cotter MA, Low PA (1991) Nerve blood flow in early experimental diabetes in rats: Relation to conduction deficits. Am J Physiol 261: E1-E8

117. Thomas PK, Tomlinson DR (1992) Diabetic and hypoglycaemic neuropathy. In: Dyck PJ, Thomas PK, Griffin JW, Low PA, Poduslo JF (eds) Peripheral neuropathy. W. B. Saunders Co., Philadelphia, London, Toronto, Montreal, Sydney, Tokyo, pp. 1219-1250

118. Nukada H (1986) Increased susceptibility to ischemic damage in streptozocin-diabetic nerve. Diabetes 35: 1058-1061

119. Fukunaga K, Miyamoto E (1998) Role of MAP kinase in neurons. Mol Neurobiol 16: 79-95

120. Derkinderen P, Enslen H, Girault JA (1999) The ERK/ MAP-kinases cascade in the nervous system. Neuroreport 10:R24-R34

121. Gómez N, Cohen P (1991) Dissection of the protein kinase cascade by which nerve growth factor activates MAP kinases. Nature 353: 170-173

122. Volonté C, Angelastro JM, Greene LA (1993) Association of protein kinases ERK1 and ERK2 with p75 nerve growth factor receptors. J Biol Chem 268: 21410-21415

123. Thomas SM, DeMarco M, D'Arcangelo G, Halegoua S, Brugge JS (1992) Ras is essential for nerve growth factorand phorbol ester- induced tyrosine phosphorylation of MAP kinases. Cell 68: 1031-1040

124. Minden A, Lin A, McMahon M et al. (1994) Differential activation of ERK and JNK mitogen-activated protein kinases by Raf-1 and MEKK. Science 266: 1719-1723

125. Hirsch DD, Stork PJ (1997) Mitogen-activated protein kinase phosphatases inactivate stress- activated protein kinase pathways in vivo. J Biol Chem 272: 4568-4575

126. Lannuzel A, Barnier JV, Hery C et al. (1997) Human immunodeficiency virus type 1 and its coat protein gp120 in- duce apoptosis and activate JNK and ERK mitogen-activated protein kinases in human neurons. Ann Neurol 42: $847-856$

127. Kaplan DR, Stephens RM (1994) Neurotrophin signal transduction by the Trk receptor. J Neurobiol 25: 1404-1417

128. Kaplan DR, Miller FD (1997) Signal transduction by the neurotrophin receptors. Curr Opin Cell Biol 9: 213-221

129. Casaccia-Bonnefil P, Kong HY, Chao MV (1998) Neurotrophins: the biological paradox of survival factors eliciting apoptosis. Cell Death Differentiation 5: 357-364

130. Casaccia-Bonnefil P, Carter BD, Dobrowsky RT, Chao MV (1996) Death of oligodendrocytes mediated by the interaction of nerve growth factor with its receptor $\mathrm{p} 75$. Nature 383: 716-719

131. Aloyz RS, Bamji SX, Pozniak CD et al. (1998) P53 is essential for developmental neuron death as regulated by the TrkA and p75 neurotrophin receptors. J Cell Biol 143: 1691-1703

132. Ladiwala U, Lachance C, Simoneau SJJ, Bhakar A, Barker PA, Antel JP (1998) p75 neurotrophin receptor expression on adult human oligodendrocytes: Signaling without cell death in response to NGF. J Neurosci 18: 1297-1304

133. Jakobsen J, Brimijoin S, Skau K, Sidenius P, Wells D (1981) Retrograde axonal transport of transmitter enzymes, fucose-labeled protein, and nerve growth factor in streptozotocin-diabetic rats. Diabetes 30: 797-803

134. Schmidt RE, Grabau GG, Yip HK (1986) Retrograde axonal transport of $\left[{ }^{125} \mathrm{I}\right]$ nerve growth factor in ileal mesenteric nerves in vitro: effect of streptozotocin diabetes. Brain Res 378: 325-336

135. Fernyhough P, Diemel LT, Hardy J, Brewster WJ, Mohiuddin L, Tomlinson DR (1995) Human recombinant nerve growth factor replaces deficient neurotrophic support in the diabetic rat. Eur J Neurosci 7: 1107-1110

136. Delcroix JD, Michael GJ, Priestley JV, Tomlinson DR, Fernyhough P (1998) Effect of nerve growth factor treatment on $\mathrm{p} 75^{\mathrm{NTR}}$ gene expression in lumbar dorsal root ganglia of streptozocin-induced diabetic rats. Diabetes 47: 1779-1785

137. Maeda K, Fernyhough P, Tomlinson DR (1996) Regenerating sensory neurones of diabetic rats express reduced levels of mRNA for GAP-43, gamma-preprotachykinin and the nerve growth factor receptors, trkA and p75 NGFR. Mol Brain Res 37: 166-174

138. Boulton TG, Nye SH, Robbins DJ et al. (1991) ERKs: a family of protein-serine/threonine kinases that are activated and tyrosine phosphorylated in response to insulin and NGF. Cell 65: 663-675

139. Schmidt RE, Beaudet LN, Plurad SB, Dorsey DA (1997) Axonal cytoskeletal pathology in aged and diabetic human sympathetic autonomic ganglia. Brain Research 769: 375-383

140. Schmidt RE, Dorsey D, Parvin CA, Beaudet LN, Plurad SB, Roth KA (1997) Dystrophic axonal swellings develop as a function of age and diabetes in human dorsal root ganglia. J Neuropath Exp Neurol 56: 1028-1043 